Vol. 1, No. 2, 2020

ISSN (ONLINE) 2597-0593

DOI 10.7146/njlis.v1i2.121791

(c) CC BY-NC-ND 4.0

Håkon Larsen, Professor, Department of Archivistics, Library and Information Science, Oslo

Metropolitan University, Norway, hakon.larsen@oslomet.no

Per Aleksander Solheim, Senior Librarian, Library of Medicine and Science, University of Oslo

Library, Norway, perasolh@uio.no

\title{
Den digitale offentligheten \\ i kultur- og \\ bibliotekpolitikken
}

\begin{abstract}
Echo chambers, fake news, filter bubbles and algorithms have been framed as great threats to our contemporary democracies and public spheres. In the Nordic countries, the state plays an active role in sustaining democracy and the public sphere through culture and knowledge policies. The Norwegian Government have over the last years presented a white paper on overall cultural policy and a library strategy document. Both documents address the effects of digital technology on democracy, and how culture institutions in general and libraries in particular can help sustain our democracies in changing times. In this article, we study these and preceding documents on culture and library policies. We analyze how they address digital technology and how they see culture and library policies as providing solutions to digital threats to democracy and the public sphere. Furthermore, we study what notion of democracy and the public sphere are prevalent in Norwegian cultural policies. The results show that the Government view culture as a remedy against a fragmented public sphere, and that libraries play a key role as providers of digital guidance and teaching.
\end{abstract}

Keywords: public sphere, Habermas, cultural policy, library policy, Norway, digital technology

\section{Innledning}

Den digitale teknologien medfører store endringer i offentligheten og vi har under 2000-tallet fått en rekke begreper for å forstå og teoretisere disse endringene: Cass Sunstein $(2001,2009,2018)$ har skrevet tre bøker om frykten for en fragmentert offentlighet og dannelsen av ekkokamre, og Eli Pariser (2011) bygget videre på denne tenkningen med sin bok om filterbobler. Evgeny Morozov 
(2012) har kommet med sterk kritikk av den naive vestlige holdningen om at så lenge nasjoners befolkning har tilgang til internett og fri informasjon, vil demokratiet trenge seg frem naturlig, og Shoshana Zuboff (2019) har beskrevet hvordan de store nettgigantene st $\varnothing v s u g e r$ nettet for personlige data, og selger disse til tredjeparter som benytter de til å produsere adferdsmodeller for markedsføring eller politisk kommunikasjon.

I de nordiske landene har vi sterke, aktive og liberale stater som indirekte har sterk påvirkning på sivile institusjoner innen kultur-, medie-, utdannings- og forskningssektoren. Staten er i de nordiske landene en sterk bidragsyter til å opprettholde en kritisk og uavhengig offentlighet, basert på prinsippet om armlengdes avstand (Engelstad, Larsen og Rogstad, 2017). I Norge har vi også grunnlovsfestet at "det påligger statens myndigheter å legge forholdene til rette for en åpen og opplyst offentlig samtale" (Grunnloven, 2004, § 100). Under 2000-tallet har bibliotekene fått et tydelig oppdrag overfor demokratiet og offentligheten, i kombinasjon med deres tradisjonelle oppdrag om å fremme folkeopplysning og dannelse. Dette samfunnsoppdraget blir tydelig kommunisert gjennom tittelen på Norges siste bibliotekstrategien - Rom for demokrati og dannelse (Kulturdepartementet og Kunnskapsdepartementet, 2019).

Med tanke på den digitale teknologiens transformasjon av offentligheten og bibliotekenes samtidige samfunnsoppdrag synes vi det er interessant å undersøke hvilke strategier og visjoner norske myndigheter har for bibliotekene $\mathrm{i}$ det digitale informasjonssamfunnet, med alle dets muligheter, utfordringer og problemer. Gjennom denne artikkelen vil vi derfor søke å svare på spørsmålet: Po̊ hvilken måte beskriver Kulturdepartementet og Kunnskapsdepartementet i de siste dokumentene om kultur- og bibliotekpolitikk de utfordringer som digital informasjonsteknologi gir for demokratiet og offentligheten, og hvordan beskriver de eventuelle politiske løsninger på disse utfordringene?

I arbeidet med å svare på dette spørsmålet, vil vi i dokumentene se nærmere på hvordan bibliotekenes rolle som aktør i møte med det digitale informasjonssamfunnets utfordringer beskrives. Videre vil vi undersøke hvilken grunnleggende demokrati- og offentlighetsforståelse som kan utledes av Kulturdepartementets dokumenter om generell kulturpolitikk og Kulturdepartementet og Kunnskapsdepartementets dokumenter om bibliotekpolitikk produsert under 2000-tallet. ${ }^{i}$ Et teoretisk perspektiv på demokrati- og offentlighet som har hatt spesielt stor innflytelse på norsk samfunnsforskning er utviklet av Jürgen Habermas. På grunn av den nordiske tradisjonen for at forskere sitter som medlemmer i ekspertutvalg som leverer uavhengige og kunnskapsbaserte forslag til politikkutforming (Holst, 2019; Engelstad, Larsen og Rogstad, 2017, s. 53), har denne tenkningen også hatt innflytelse på politikkutforming i Norge, spesielt når det kommer til spørsmål om ytringsfrihet (Kalleberg, 2015). Som det vil gå frem av denne artikkelen, har denne tenkningen også hatt innflytelse på 2000-tallets kultur- og bibliotekpolitikk. Før vi foretar en nærmere presentasjon og analyse av datamaterialet vil vi derfor gi en kort presentasjon av Habermas' tanker om demokrati og offentlighet. ${ }^{\text {ii }}$

\section{Habermas, offentligheten og demokratiet}

Den borgerlige offentlighet er et begrep Habermas (2005[1962]) brukte for å beskrive den fremvoksende offentligheten blant europeiske borgere og intellektuelle fra 1700-tallet og utover mot 1950-tallet. På denne tiden fant borgere, som regel fra et høyere samfunnslag, sammen i kaffehus i London, parisiske salonger eller tyske Tischgesellschaften (middagsselskaper) for å diskutere kunst, litteratur, økonomi og politikk, uten myndighetenes eller geistlighetens innsyn og innflytelse. Her kunne de fritt og usensurert diskutere samtidsproblematikk og danne det vi etter hvert kom til å kjenne som en offentlig opinion. Opinionsdannelsen utviklet seg parallelt med en fremvoksende fri presse, der tidsskrifter og tidlige utgaver av aviser ga borgerne en kommunikasjonskanal for videre 
samfunnsdebatt og kritikk. Dette er den spede begynnelsen på en kritisk offentlighet som kan utøve innflytelse på politiske beslutninger.

Den borgerlige offentlighet er sfæren for privatfolk samlet til publikum - et kritisk diskuterende publikum. [...] [I] den borgerlige offentlighet er det den kritiske diskursen som er offentlig, ikke personene; offentligheten er sfæren for diskursiv omgang med argumenter som er likt for alle, uten personens anseelse - og ikke for fremvisning av de deltakendes sosiale status (Høibraaten, 2005, s. XXVI).

En effektiv og fri offentlig samtale er en viktig faktor for vellykkede demokratiske systemer, siden politiske og lovgivende institusjoner som er åpne for innspill fra sivilsamfunnet og opinionen, fører til sterkere demokratiske systemer, samtidig som det også styrker deres legitimitet overfor velgerne (Finlayson, 2005, s. 108). Denne demokratimodellen, der saker av offentlig interesse diskuteres åpent for alle parter, er et kjennetegn ved det deliberative demokratiet. Habermas (2006) har selv utviklet en deliberativ demokratiteori om diskursdemokratiet hvor idealet om en borgerlig offentlighet er sentralt. For Habermas (1984) er en ideell handling i en borgerlig offentlighet en kommunikativ handling, en "sosial samhandling der to eller flere tale- og handlingskompetente aktører samordner sine individuelle handlingsplaner gjennom en språklig formidlet enighet" (Kalleberg, 2019, s. 145). Rendyrket kommunikativ handling oppstår hvis denne handlingsplanen er fri for vikarierende motiver, trusler om sanksjoner eller personlige maktinteresser som kan tvinge motparten til handling. Ifølge Habermas kan "... språklig formidlet enighet ... virke handlingsmotiverende på samme måte som sanksjoner ... Habermas hevde[r] at språklig etablert enighet hviler på det han kaller kraften $i$ det bedre argument" (Kalleberg, 2019, s. 145).

En borgerlig offentlighet er et bindeledd eller et rom mellom sivilsamfunnet og myndighetene. I dette rommet der opinion oppstår, fortrinnsvis basert på kommunikativ handling og kraften i det bedre argument, vil utvikling i kommunikasjonsteknologi ha stor innflytelse. Den lange røde tråden i utviklingen av en offentlighet kan sees fra oppfinnelsen og utbredelsen av trykkpressen, via en etablert fri presse, gjennom massemedia som radio og TV. Til sist har sosiale medier hatt en sterk innflytelse på offentlig samtale og opinionsdannelse. I sin opprinnelige teori om den borgerlige offentlighet var Habermas (2005[1962]) meget pessimistisk med tanke på massemedienes passivisering av befolkningen. Senere har han endret syn på massemedienes rolle for det deliberative demokratiet, og han har uttrykt et ambivalent syn på internett og de sosiale medienes bidrag til en felles offentlighet (Habermas, 2006; Gentikow, 2009). I denne studien vil vi unders $\varnothing$ ke hvordan ideene om det deliberative diskursdemokratiet gjør seg gjeldende i kultur- og bibliotekpolitikken, og vi vil se hvordan de norske myndighetene gjennom politikkdokumentene forholder seg til den digitale teknologiens innvirkning på demokratiet og offentligheten.

\section{Data}

Studien er basert på en analyse av de to stortingsmeldingene om allmenn kulturpolitikk produsert under 2000-tallet (Kultur- og kirkedepartementet, 2003; Kulturdepartementet, 2018), Norges eneste rene stortingsmelding om biblioteker (Kulturdepartementet, 2009) og Norges to nasjonale bibliotekstrategier (Kulturdepartementet, 2015; Kulturdepartementet og Kunnskapsdepartementet, 2019). Av disse dokumentene underkastes den siste generelle stortingsmeldingen om kulturpolitikk (Kulturdepartementet, 2018) og den sist utgitte nasjonale bibliotekstrategien (Kulturdepartementet og Kunnskapsdepartementet, 2019) en grundig analyse, siden disse er sentrale dokumenter som legger føringer for bibliotekenes samfunnsoppdrag $\mathrm{i}$ de kommende årene. ${ }^{\mathrm{iii}} \mathrm{Vi}$ har analysert dokumentene ved hjelp av et sett med koder, som presenteres i siste avsnitt av denne delen. Hva slags type dokumenter er det så vi har analysert? 
Generelle stortingsmeldinger om kulturpolitikk har siden 1970-tallet blitt presentert ca. hvert tiende år. Kulturmeldingene inneholder oppsummeringer av foregående politikk for kultursektoren og perspektiver på hvor man vil med kulturpolitikken de neste årene. At vi i 2009 fikk en egen stortingsmelding om bibliotek kan blant annet ses i sammenheng med et pågående arbeid for å revidere loven om folkebiblioteker (en revidert versjon av loven tredde i kraft i 2014). Bibliotekstrategier er en ny type politisk dokument. Den første bibliotekstrategien for 2015-2018 var tett knyttet til bibliotekmeldingen fra 2009, og behandler Nasjonalbibliotekets nye rolle som sentral utvikler av biblioteksektoren i Norge.$^{\text {iv }}$ Den siste bibliotekstrategien er utledet av den siste generelle kulturmeldingen, og fokuserer blant annet på bibliotekenes demokratiske oppdrag og dets rolle $\mathrm{i}$ møte med den digitale teknologien.

Våre resultater fra analysene vil bli presentert dokumentvis. Vi vil starte med den siste kulturmeldingen (Kulturdepartementet, 2018) etterfulgt av den siste bibliotekstrategien (Kulturdepartementet og Kunnskapsdepartementet, 2019). Deretter kommer en diskusjonsdel, sentrert rundt fire kategorier: Problemforståelse; Løsningsforslag; Bibliotekets rolle; Demokrati og offentlighet. Problemforståelse er en kategori der vi gjennomgår hvilke utviklingstrekk og utfordringer knyttet til det digitale informasjonssamfunnet som beskrives i dokumentene. Løsningsforslag inkluderer hvilke Iøsninger kulturmyndighetene har iverksatt, eller planlegger å iverksette over tid, i møte med de nevnte utviklingstrekkene og utfordringene. Bibliotekets rolle omhandler de deler av dokumentene som beskriver hvilken rolle myndighetene ser for seg at bibliotekene kan spille i møte med det digitale informasjonssamfunnet. Demokrati og offentlighet dreier seg om de tekstpartier hvor myndighetene presenterer overordnede idéer angående en opplyst offentlighet og samtale, og hvilken rolle de spiller i det norske demokratiet. Vi har kommet frem til kodene gjennom en dokumentanalyse, basert på en kvalitativ innholdsanalyse. Vi foretok først en induktiv sortering av tekstutdrag fra dokumentene etter hvordan de besvarte forskningsspørsmålet. Utdragene ble deretter sortert i fire preliminære kategorier, før en ny deduktiv lesning av kildene basert på disse kategoriene ble gjennomført. Den vekselvis induktive og deduktive analysen meislet gradvis ut de fire avgrensede kategoriene.

\section{Resultater og analyse}

Det første dokumentet vi ser på i denne delen er kulturmeldingen presentert i november 2018 av kulturminister Trine Skei Grande (Venstre) fra Erna Solbergs (Høyre) regjering. Meldingen speiler tydeligere enn de tidligere dokumentene vi har analysert (Kultur- og kirkedepartementet, 2003; Kulturdepartementet, 2009, 2015, 2018) de digitale utfordringene for informasjonssamfunnet og offentligheten, samtidig som bibliotekene blir behandlet som en sterkere aktør i møte med disse. Det andre dokumentet vi ser på er bibliotekstrategien utgitt i november 2019, som både er utledet av kulturmeldingen og bygger videre på bibliotekstrategien fra 2015 (Kulturdepartementet, 2015). Tre statsråder står som ansvarlige for den siste bibliotekstrategien: Kulturminister Trine Skei Grande (Venstre), forsknings- og høyere utdanningsminister Iselin Nybø (Venstre) og kunnskaps- og integreringsminister Jan Tore Sanner (Høyre), de to sistnevnte fra Kunnskapsdepartementet. Strategien tar for seg både folkebiblioteker, skolebiblioteker og fag- og forskningsbiblioteker.

\section{Kulturens kraft}

Innledningen til den siste kulturmeldingen, Kulturens kraft, inneholder en tydelig og alvorlig problemforståelse knyttet til demokratiutfordringer, både internasjonalt og i Norge:

Demokratiet blir utfordra, og internasjonalt ser vi at ytringsfridommen [...] og den fagleg frie stillinga til kulturinstitusjonane er under press. Tilliten til og trua på demokratiet er på vikande front fleire stader. Fleire land ser ut til å vere i ferd med å bli "seg sjølv nok" og orienterer seg innover. Samtidig ser vi at det veks fram digitale ekkokammer, og at store globale aktørar i stadig 
større grad legg premissane for dei vala vi gjer som forbrukarar og kultur- og mediebrukarar. Dette er utviklingstrekk som legg press på mangfaldet av ytringar og kulturuttrykk. Folkestyret står sterkt i Noreg, men også hos oss blir demokratiet meir sårbart. Vi må jobbe aktivt med å vise fram verdien av dei grunnleggjande elementa i eit demokrati, som ytringsfridom, tolerante fellesskap og respekt for individet (Kulturdepartementet, 2018, s. 7). ${ }^{\mathrm{v}}$

Sitatet gir en tidsriktig vurdering av hvilke utfordringer man ser i informasjonssamfunnet. Digitale ekkokamre, og det at store globale aktører legger premissene for en fungerende offentlighet blir eksplisitt nevnt. Det nevnes også at store globale aktører i økende grad legger premissene for våre kultur- og medievaner, og våre valg som forbrukere. Dette har klare paralleller med temaet i Zuboffs (2019) bok, der store teknologiselskaper høster personlige data for å utvikle effektive algoritmer. Ifølge Zuboff er målet å produsere algoritmer som kan forutsi brukeradferd, for på den måten å markedsføre produkter med langt større effektivitet enn ved ordinær annonsering eller reklame. Hun beskriver hvordan høsting og salg av store datamengder har blitt et stort globalt marked, og foreslår løsninger på disse utfordringene ved for eksempel ny lovgivning for å ta vare på personvern og personlige data. Senere i kulturmeldingen kan vi lese:

Den teknologiske utviklinga går i dag raskare enn før. Dette gir nye moglegheiter, men skaper òg nye etiske dilemma. Eit $n \varnothing k$ kelord for teknologiutviklinga er omvelting, som inneber at vi må vente det uventa. Vi er omgitt av ein stadig meir omfattande og kompleks teknologisk infrastruktur som ingen eigentleg er i stand til å føreseie korleis vil utvikle seg. Det einaste som er sikkert, er at den teknologiske utviklinga vil gå svært raskt, og at vi også i framtida vil sjå store endringar i både teknologiske moglegheiter og brukarvanar (s. 22).

I alle dokumentene vi har analysert (Kultur- og kirkedepartementet, 2003; Kulturdepartementet 2009, 2015, 2018; Kulturdepartementet og Kunnskapsdepartementet, 2019) er man opptatt av hastigheten på og omfanget av den teknologiske utviklingen, og hvordan denne kan føre til omveltninger i samfunnet. Når man i tillegg fremhever at det nær sagt er umulig å spå en fremtid på grunn av den teknologiske utviklingen, setter politikerne seg i prinsippet i baksetet og lar de store teknologiselskapene styre utviklingen, akkurat slik Zuboff (2019) og Morozov (2012) har advart mot.

I et eget delkapittel om media og den offentlige samtalen omtales flere digitale utfordringer. Det innledes med en beretning om hvordan mye av samhandlingen mellom mennesker, den offentlige samtalen og den kulturelle deltakelsen, flytter seg fra fysiske til digitale rom, og at vi hele tiden har tilgang til et verdensrepertoar av informasjon og kulturuttrykk (s. 23). Videre påpekes det at selv om mennesker tilbringer mindre tid med hverandre i fysiske omgivelser fører det til økt behov for offentlige steder der vi kan møtes ansikt-til-ansikt.

I samme kapittel blir ekkokamre og bekreftelsestendenser beskrevet som problematisk for det offentlige ordskiftet:

I større eller mindre grad har vi alle ein tendens til å oppsøkje og tru på informasjon vi allereie er einige i. Slike stadfestingstendensar blir forsterka av digitaliseringa. $\$ \varnothing$ kjemotorar og medieinnhald blir $\mathrm{i}$ aukande grad styrte av algoritmar som er laga slik at dei kan forsterke denne tendensen. Innhald blir filtrert og styrt av preferansar og tidlegare bruk, og vi blir i mindre grad eksponerte for andre perspektiv og meiningar (s. 23).

Dette er første gang disse problemene nevnes i klartekst i de analyserte dokumentene, og gir en tydelig problemforståelse angående dette temaet. Sitatet gir i tillegg implisitt uttrykk for at filterboblene (Pariser, 2011) har blitt et potensielt problem for det offentlige ordskiftet. Filterboblene har den effekten at nettlesere, $s \varnothing$ kemotorer eller sosiale medier kan filtrere bort informasjon som 
den tror du ikke vil ha interesse av, basert på ens tidligere historikk og aktivitet på internett. Herunder ligger også problemet med at når vi ikke blir eksponert for meningsmangfold eller alternative perspektiver, er det ren reell svekkelse av ytringsrommet, og i ytterste konsekvens også det deliberative demokratiet. Der ekkokamre for Sunstein $(2001,2009)$ var noe vi selv skapte gjennom vår online-aktivitet, er filterbobler for Pariser (2011) noe teknologiselskapene skaper for oss gjennom sine algoritmer.

I samme delkapittel blir også andre digitale utfordringer nevnt som potensielle trusler for demokratiet og en velfungerende offentlighet:

Tilgangen til informasjon har aldri vore større, men ikkje all informasjon er rett eller truverdig. Det kan handle om faktafeil, ryktespreiing, svindel eller politisk motivert desinformasjon. Det blir mottakaren sitt ansvar å vurdere kvalitet, relevans og sanning i informasjonen (s. 23).

Her blir falske nyheter og desinformasjon tydelig fremstilt som samfunnsproblemer. I samme avsnitt nevnes resultatet av en unders $\varnothing$ kelse utført av Medietilsynet, der en stor andel av befolkningen mener de hver uke eller oftere opplever å se nyheter de ikke opplever som sanne. Det vektlegges at det er svært viktig at: "så mange som råd kan kommunisere og ta del i den offentlege samtalen på ein måte som fremjar forståing mellom menneske. Dette inneber at befolkninga må ha evne og vilje til å forstå ulike ytringar og korleis ulike mottakarar vil forstå og oppleve ytringar" (s. 23).

Den sterke veksten i ytringskanaler som digitale medier har medført, erkjennes å ha store implikasjoner for den offentlige samtalen. Dette setter tydeligere krav til befolkningens kildekritikk, informasjons- og mediekompetanse. Sosiale medier nevnes også som en faktor som ytterligere påvirker dette ytringslandskapet:

digitale informasjons- og ytringsmoglegheiter, blant anna gjennom sosiale medium, endrar både kvardagslivet og den offentlege samtalen på mange og djuptgåande måtar. Eit godt utvikla og levande demokrati er avhengig av ein opplyst opinion og open og fri meiningsutveksling. Oppfatningar må brynast mot kvarandre (s. 23).

Her er nok en henvisning til idéen om at et sterkt demokrati fordrer en opplyst befolkning med gode ytringsmuligheter, og implisitt hvordan omveltninger og endringer i kommunikasjonsteknologi kan utfordre dette idealet. "Dagens informasjonssamfunn stiller store krav til at menneska utviklar kritisk sans og utvidar forståingshorisonten, for å kunne vurdere kjelder, undersøkje kva som er sant og usant, og gjere sjølvstendige val” (s. 38).

I denne stortingsmeldingen fremmes kultursektoren som en del av løsningen på splittede offentligheter, og som en motvekt mot teknologiens mulig negative innflytelse på demokratiet. Det skrives at "kulturlivet må vere med på å rettleie folk, fremje kritisk tenking og læring, og streve etter kvalitet og kunnskap i tilfanget av informasjon og kulturelt innhald" (s. 38). Det nevnes derimot ingen konkrete eksempler på hvordan dette kan omsettes til praksis. I forbindelse med at kulturlivet skal kunne delta som et bolverk mot digitale utfordringer $\mathrm{i}$ det offentlige rommet, vises det til at kulturinstitusjoner har høy tillitt i befolkningen. I kraft av denne tilliten kan: "kulturverksemder som arkiv, bibliotek og museum fremje tillit, autentisitet og relevans. Aktørar i kulturlivet kan utgjere ei positiv kraft, vere ei motvekt mot fragmentering av den offentlege samtalen og medverke til å utløyse teknologiens potensial for å gjere kulturtilbod tilgjengelege for fleire" (s. 38). Kultursektoren ses som en sentral aktør for å sikre

ei felles offentlegheit, der meiningar står mot kvarandre og blir delte på tvers av interessemotsetningar. Kulturlivet skal vekkje engasjement blant folk og leggje til rette for 
meiningsbryting og eit mangfald av ytringar. Leseevne og leselyst er ein nøkkel til danning og refleksjon (s. 39).

En annen målsetning som skal kunne styrke det offentlige ordskiftet mot fragmentering og ekkokammerdannelse (Sunstein, 2001, 2009, 2018) er at kultur- og kunnskapssektoren skal forene krefter og interesser for å motvirke disse utfordringene. Dette blir påpekt i kapittelet om danning og demokratibygging: "Både kultursektoren og kunnskapssektoren medverkar [...] til danning og demokratibygging. Samarbeid på tvers kan være ein styrke for å byggje sterkare medvit om kunst og kultur som ytringar og kor mykje kulturen betyr for danning, tilhøyrsle og kunnskapsutvikling" (s. 80). Samarbeid på tvers mellom for eksempel grunnskolen og kultursektoren skal medvirke til en sterkere dannelsesprosess hos barn og unge.

I et eget kapittel om danning og demokratibygging finnes overordnede beskrivelser av hvilke demokrati- og offentlighetssyn som preger denne kulturmeldingen. Her blir flere gjengangere om demokratiets bånd til en opplyst og dannet befolkning repetert. Vi får blant annet høre at: "Eit demokratisk samfunn føreset at menneska har kunnskap om og forstår samfunnet dei er ein del av, og at dei har høve og evne til å uttrykkje seg og ta aktivt del i samfunnet” (s. 79).

Litt senere presenteres viktigheten av menneskers dannelse for demokratiet: "Danning handlar om å setje enkeltmenneske i stand til å vere aktive borgarar i samfunnet, uttrykkje seg og ta sjølvstendige val som byggjer på forståing og respekt for andre. Dette er med på å byggje demokrati" (s. 79). At befolkningens evne til kritisk tenkning og beslutningstaking er et premiss for demokratisk levedyktighet er noe som går igjen i alle de analyserte stortingsmeldingene (Kultur- og kirkedepartementet, 2003; Kulturdepartementet, 2009, 2018).

I norsk kulturpolitikk er det grunnleggende at kulturbruk skal sette oss i stand til å fungere som borgere, noe som også gjenspeiles i meldingens tittel, Kulturens kraft. Tittelen kan fortolkes som at kultur har kraft til å myndiggjøre, danne og hjelpe mennesker i å oppnå kritisk og selvstendig tenkning. I meldingen skrives det også om mediekompetanse som en viktig komponent $i$ dannelse og demokratiutvikling:

Mediekompetanse og digital dømmekraft er viktig for danning og demokratibygging. Mediekompetanse handlar om kunnskap om korleis media fungerer, og evne til å vurdere kvalitet, relevans og sanning i den informasjonen ein finn. Digital dømmekraft dreier seg om evne til kritisk refleksjon, blant anna knytt til personvern, nettvett og opphavsrett (s. 79).

Vi får i dette utdraget en klar og tydelig henvisning til at mediekompetanse, og underforstått også at informasjonskompetanse og kildekritikk, er viktige faktorer for demokratisk utvikling. Begreper som digital dømmekraft, kritisk refleksjon og nettvett blir beskrevet som ferdigheter av betydning, både for individuell dannelse og demokratisk deltakelse. Disse ferdighetene beskrives som viktige for et opplyst og rasjonelt ordskifte, og en kritisk borgerlig offentlighet.

I et annet kapittel, som omhandler kulturlivets samfunnsbyggende kraft, henvises det til den reviderte ytringsfrihetsparagrafen og de tre grunnprinsippene ytringsfriheten baseres på. ${ }^{\mathrm{vi}}$

Sanningsprinsippet inneber at ein best kjem fram til sanning gjennom meiningsutveksling der påstandar blir korrigerte i møte med andre meiningar. I autonomiprinsippet ligg det at det krevst ein viss kompetanse for å kunne fungere som sjølvstendig individ i eit ope samfunn. Denne kompetansen oppnår kvar enkelt innbyggjar ved å møte andre, høyre argumenta deira og bli utfordra av alternative perspektiv. Demokratiprinsippet føreset ei open og kritisk 
meiningsutveksling som kan vere med på å gi betre innsikt og dermed betre avgjerder, jf. sanningsprinsippet (s. 15).

Dette tekstutdraget inneholder flere av de sentrale forutsetningene for en rasjonell og kritisk offentlighet etter Habermas' ideal. $\AA$ delta i det deliberative demokratiet forutsetter et uenighetsfellesskap der meningsmangfold er en forutsetning for et samfunns utvikling og fremdrift. For å gjøre dette uenighetsfellesskapet levedyktig behøves en kompetent befolkning som er i stand til å fatte rasjonelle beslutninger, og kulturmeldingen hevder at kultursektoren kan spille en rolle $\mathrm{i}$ dette arbeidet.

Å delta i kulturlivet inneber at ein blir vand til å møte eit mangfald av meiningar og ytringsformer, også meiningar ein er usamd i eller misliker. Slik kan kulturlivet setje oss betre i stand til å handtere spenningar i samfunnet som utfordrar openheit og toleranse, og medverke til å styrkje det fellesskapet vi treng for å byggje demokrati (s. 16).

Her fremmes tanken om at kulturlivet kan være en sentral bidragsyter for å underbygge demokratiske prosesser. Kulturens demokratiske innvirkning blir sett på som en "arena for den openheita og kritikken eit demokratisk samfunn er avhengig av" (s. 16).

I forbindelse med den reviderte ytringsfrihetsparagrafen nevnes infrastrukturkravet som

inneber at staten pliktar å medverke aktivt til etablering og drift av kanalar ut i det offentlege rommet, slik at det verkeleg blir mogleg for individ og grupper å ytre seg. Statens oppgåve er med dette utvida frå passivt å avstå frå inngrep i ytringsfridommen til aktivt å leggje forholda til rette for ytringsfridom (s. 17). vii $^{\text {vi }}$

I et kapittel om digitale muligheter for samfunnet beskrives den digitale omveltningen som at den kan ha positive ringvirkninger for offentligheten. Ved at kulturuttrykk blir digitalisert gis de større spredningspotensiale, noe som "er med på å opne ei ny verd for mange, og det ligg ei demokratisk kraft i dette dersom teknologien blir brukt rett. Då kan den digitale teknologien vere inkluderande og moderniserande" (s. 49). Den nye teknologien gir også befolkningen større medvirkning og endrer dynamikken for kommunikasjon i den kulturelle offentligheten.

I vår tid blir terskelen for ytring, deltaking og interaksjon lågare. Dette er demokrati i praksis. Nordmenn ligg i forkant når det gjeld bruk av ny teknologi, og vi bruker stadig meir tid på digitale plattformer. Digitale plattformer fungerer som virtuelle møteplassar der vi uttrykkjer oss, utvekslar idear og erfaringar, og les, høyrer og engasjerer oss i ulike typar innhald (s. 49).

Etter de kritiske tekstene om ekkokamre og en stadig mer fragmentert offentlighet viser Kulturdepartementet, som vi ser over, også optimisme over den digitaliserte offentligheten. Lavere terskel for ytringer i en digital offentlighet fører formodentlig også til økende demokratisk deltakelse. I likhet med litteraturen om den digitale offentligheten (se Valtysson 2020), vises det her både til dystopiske og utopiske visjoner for den digital teknologiens endring av den offentlige samtalen.

I meldingen nevnes folkebiblioteksektoren som et satsingsområde, og da i forbindelse med å $\varnothing$ ke bibliotekenes rolle som en offentlig møteplass og kunnskapsarena i lokalmiljøet. Teksten henviser til at dette emnet vil bli mer detaljert og utførlig forklart i bibliotekstrategien for 2020-2023, som vi nå skal se nærmere på. 


\title{
Rom for demokrati og dannelse
}

I bibliotekstrategien er det fyldig beskrevet hvilke samfunnsutfordringer man fors $\varnothing$ ker å im $\varnothing$ tekomme med bibliotekenes nye roller. Allerede i forordet uttrykkes det bekymring for hvordan utfordringer ved digital informasjonsteknologi og mengden informasjon vi omgås kan ha konsekvenser for vår informasjonstilegnelse:

\begin{abstract}
Vi har tilgang til mer kunnskap og kultur enn noensinne. Men det at vi har tilgang til en nesten uendelig mengde kunnskap betyr ikke at vi oppsøker eller benytter oss av den. Tvert om ser vi faktisk at kunnskap og opplysning på nettet konkurrerer og tidvis taper for falske nyheter, rykter og propaganda. Regjeringen vil at bibliotekene skal være en motkraft til dette (Kulturdepartementet og Kunnskapsdepartementet 2019, s. 5).
\end{abstract}

De ansvarlige departementene erkjenner at informasjonsmengden er en utfordring for menneskers kritiske sans og informasjonskompetanse, og de ser for seg biblioteket som en potensiell motvekt mot dette. Strategidokumentet bygger i stor grad videre på problemforståelsen fra den foregående kulturmeldingen (Kulturdepartementet, 2018), noe som kommer frem i dette sitatet fra det første kapittelet om regjeringens bibliotekpolitikk: "Dagens informasjonssamfunn stiller store krav til at menneska utviklar kritisk sans og utvidar forståingshorisonten, for å kunne vurdere kjelder, unders $\varnothing \mathrm{kje} \mathrm{kva} \mathrm{som} \mathrm{er} \mathrm{sant} \mathrm{og} \mathrm{usant,} \mathrm{og} \mathrm{gjere} \mathrm{sjølvstendige} \mathrm{val"} \mathrm{(s.} \mathrm{7).} \mathrm{Lignende} \mathrm{formuleringer} \mathrm{finnes}$ også i de foregående stortingsmeldingene om kultur- og bibliotekpolitikk (Kultur- og kirkedepartementet, 2003, Kulturdepartementet, 2009, 2018), noe som befester den gjentakende forestillingen om at informasjonsmengden og den varierende informasjonskvaliteten stiller sterke krav til samtidens borgere.

I bibliotekstrategien henvises det til regjeringens politiske plattform og utsagn om at regjeringen vil satse på folke- og skolebibliotekene "blant annet gjennom å styrke arbeidet med digitale plattformer og nye modeller for drift av bibliotek" (s. 7). Bedre samarbeid mellom folkebiblioteksektoren og skoleog fagbibliotekene foreslås som en Iøsning for å styrke bibliotekene som en kunnskapsinstitusjon for framtiden. Vi ser også forslag til kompetanseheving innen digitale medier og kildekritikk hos bibliotekfaglige ansatte. I et kapittel om kompetanseheving blir vi, etter en innledende tekst om hvilke utfordringer digital informasjonsteknologi kan ha for biblioteksektoren, fortalt at bibliotekansatte skal være:

veiledere i kilder på nettet. Biblioteket skal være et naturlig sted å henvende seg for den som $\emptyset$ nsker å skille mellom ekte og falske nyheter, mellom gode og dårlige kunnskapskilder. Personale med bred og oppdatert kompetanse er avgjørende for at bibliotekene skal kunne utføre sine samfunnsoppgaver og levere et godt bibliotektilbud. Oppbygging av ny kompetanse hos bibliotekarene er avgjørende for å utvikle nye tjenester og et fremtidsrettet bibliotektilbud (s. 43).

Det er en konkret målsetning at biblioteket skal være et naturlig sted å oppsøke for kompetanse innen kildekritikk og nettvett. I praksis er det likevel grunn til å anta at bibliotekarer i liten grad får denne typen henvendelser i sitt daglige referansearbeid.

En annen og mer spesifikk målsetning som nevnes i strategien angår kompetanseheving blant skolebibliotekarene. I forbindelse med økningen i digital kompetanse blant bibliotekarer skrives det at når man lokalt vurderer kompetanseheving "bør man også vurdere om det er behov for kompetanseutvikling for skolebibliotekansvarlige for å styrke medielesningskompetansen i skolen. Slik kompetanse kan blant annet bidra til at barn og unge rustes til å skille mellom falske og ekte nyheter" (s. 43). Dette kan tolkes som et konkret tiltak under det ofte gjentatte argumentet om bibliotekfaglig samarbeid på tvers av sektorer for å styrke informasjonskompetanse og 
dannelsesprosesser for brukerne. Skolebibliotekene blir dermed tillagt en tydelig rolle for utvikling av medie- og informasjonskompetanse. ${ }^{\text {viii }}$

Strategien inneholder fyldige beskrivelser av hvilken ny og modernisert rolle man $\emptyset$ nsker at biblioteket skal spille i det digitale samfunnet. I forordet blir forbindelsen mellom demokrati og kunnskapstilgang nevnt, og det fortelles hvordan biblioteket skal forsterke dette samspillet: "Demokratiet er ikke gitt, derfor må strategien legge til rette for at bibliotekene kan fungere som kunnskapsarenaer som gir brukerne tilgang til kvalitetssikret informasjon og forskning" (s. 4).

Det vises til at bes $\varnothing$ ket til bibliotekene har $\varnothing \mathrm{kt}$ med flere prosent siden den første bibliotekstrategien. Mye av æren for dette tilfaller at man med forrige strategi arbeidet for å styrke bibliotekenes rolle som møteplasser og debattarenaer (Kulturdepartementet, 2015). I et senere avsnitt får vi også et historisk sveip over bibliotekets rolle som kunnskapsinstitusjon, folkeopplyser og dannelsesagent, og hvordan denne rollen skal befestes for fremtiden:

\begin{abstract}
Folkeopplysning handler om biblioteket som kunnskapsarena, der befolkningen skal ha tilgang til forskningen og kildene, og biblioteket skal bidra til utvikling av kritisk tenkning og digital dømmekraft i befolkningen. Helt fra de norske folkeboksamlingene ble etablert for nesten 200 år siden har biblioteket hatt rollen som dannelsesinstitusjon. Bibliotekansatte har jobbet for at folk skal lese og ha tilgang til kunnskap og kultur. Rollen som formidler og en som åpner opp samlinger og forskning, er fremdeles like aktuell. Den kan styrkes gjennom mer samarbeid mellom folkebibliotek og universitet- og høyskolebibliotek (s. 4).
\end{abstract}

Mer samarbeid mellom folke- og fagbibliotekene blir sentralt i møtet med sterkere behov for informasjonskompetanse og kildekritikk i befolkningen, et poeng som repeteres også under kapittelet om regjeringens bibliotekpolitikk (s. 7). Der heter det seg at målet med å koordinere utviklingsoppgavene mellom folke-, skole-, fag- og forskningsbibliotek er å "videreutvikle bibliotekene som relevante og viktige institusjoner i fremtiden, som skal bidra til folkeopplysning og dannelse for befolkningen"(s. 7).

I strategidokumentet konstateres det fra start at "bibliotekene er demokratihus. Fra Nasjonalbiblioteket til folkebibliotek, skolebibliotek og fag- og forskningsbibliotek. Sammen utgjør disse viktig demokratisk infrastruktur og er en grunnstamme i demokratiet” (s. 4). I tillegg til å være folkeopplyser og dannelsesagent kan bibliotekene være integreringsakt $\varnothing r$, da de kan bringe borgere av forskjellige etnisiteter og kulturer, sosiale lag og bakgrunner sammen. "[K]ommuner som utvikler sine bibliotek til å bli gode og tilgjengelige er demokratifremmende og skaper felleskap" (s. 4), slår strategien fast. Videre fremheves det at lik tilgang til informasjon, kunnskap og kultur, uansett bakgrunn, er sosialt utjevnende fordi "tilgang til kunnskap er en forutsetning for å delta i samfunnslivet, og det motvirker ulikheter i befolkningen" (s. 4).

\title{
Diskusjon
}

I denne delen vil vi se på funnene fra analysen i lys av de fire kategoriene vi viste til i seksjonen om datamaterialet: problemforståelse, løsningsforslag, bibliotekets rolle, demokrati og offentlighet.

\section{Problemforståelse}

I den siste stortingsmeldingen om allmenn kulturpolitikk blir det tydelig beskrevet hvordan ytringsfriheten og demokratiet er under press fra fremveksten av ekkokamre (Sunstein 2001, 2009, 2018), de store teknologiselskapenes innflytelse på den digitale infrastrukturen (Zuboff, 2019), og effekten av algoritmisk skapte filterbobler (Pariser, 2011). Falske nyheter og desinformasjon blir også nevnt som trusler for samfunnet, og det vises til at et betydelig antall nordmenn har problemer med 
å skille sant og usant i informasjonskilder på internett. Medie- og informasjonskompetanse, samt kildekritikk, blir beskrevet som forebyggende tiltak og som et løsningsforslag til problemene.

Utfordringene som nevnes i denne kulturmeldingen har det til felles at de kan være hindre for reell kommunikativ handling (Habermas, 1984) i det offentlige ordskiftet. Desinformasjon og falske nyheter er skapt for å villede, mens ekkokamre og filterbobler hindrer kommunikativ handling i en felles offentlighet ved at motstemmer eller alternative verdisyn blir usynlige for borgerne. Kraften $i$ de bedre argumenter vil ha dårlige levevilkår i et slikt miljø, og det vil kunne lede til at en felles offentlighet forvitrer til fordel for en rekke deloffentligheter som snakker forbi hverandre.

Samtidig er det viktig å fremheve at disse kritiske perspektivene på demokratiets forvitring med den digitale teknologien også har blitt kritisert. Axel Bruns (2019) har kritisert begrepene ekkokamre og filterbobler for å være utydelig definerte, og derfor vanskelige å benytte i studier. Han har videre sagt at ekkokamre hverken er et nytt fenomen eller et stort problem, da de har eksistert i ulike former til alle tider, siden mennesker har en iboende tendens til å foretrekke sosial omgang med et enighetsfellesskap. Et annet argument Bruns bruker er at et absolutt ekkokammer kun kan eksistere i teorien. Selv mennesker som er del av et sterkt ekkokammer, slik vi oppfatter uttrykket i ordinær forstand, vil ha andre informasjonskilder de eksponeres for, enten aktivt eller passivt. Lignende argumenter for at effekten av ekkokammere overdrives finnes i Informerte Borgere (Moe et al., 2019): Etter å ha redegjort for den offentlige frykten for den potensielt ødeleggende kraften i falske nyheter, filterbobler og ekkokamre, konkluderer forfatterne med at "verken vår eller tidligere forskning finner bevis på denne typen ekstreme effekter" (s. 81). Det kan med andre ord være grunn til å tro at frykten for disse utfordringene kan ha et anslag av moralsk panikk i en verden som kan oppfattes som urolig og i endring.

I bibliotekstrategien fra 2019 er det fyldig beskrevet hvilke utfordringer man ser for seg at det digitale informasjonssamfunnet kan by på. Siden denne strategien er direkte utledet av den generelle kulturmeldingen fra 2018 overlapper problemforståelsene i disse dokumentene hverandre. Blant problembeskrivelser som går igjen er at veksten i den digitale informasjonsmengden utfordrer befolkningens informasjonskompetanse og evne til kildekritikk. De deler også en bekymring for ekkokammerdannelser og faren for at fremmede makter skal manipulere opinionsdannelsen.

\section{Løsningsforslag}

I Kulturens kraft fremstilles kultursektoren som en sentral del av Iøsningen på de utfordringer den digitale teknologien gir for demokratiet og offentligheten. Dette er fordi kulturuttrykk fremmer kritisk tenkning og læringsvilje. Kulturlivet skal rettlede og etterstrebe kvalitet i en offentlighet som blir stadig mer fragmentert. Man har en idé om at menneskers dannelse og utvikling via kulturelle uttrykk skal forebygge splittede offentligheter. Dette skjer ved at kulturen evner å samle mennesker med forskjellige bakgrunner og meninger i en inkluderende offentlighet med rom for meningsbrytning og et mangfold av ytringer. Veien til dette målet går blant annet gjennom å fremme leseevne og leselyst. En del av dette er tanker som Habermas (2005[1962]) formulerte i sin teori om den borgerlige offentlighet. Den første borgerlige offentligheten Habermas beskrev var en litterær offentlighet, et rom for kritisk tenkning og meningsutveksling blant et lesende publikum. Idéen om tilegnelse av kulturelle uttrykk som utgangspunkt for en felles offentlighet er altså ingen ny tanke. Tanken om at kulturlivet er en uerstattelig premissleverandør for en fungerende og levedyktig offentlighet er et grunnleggende perspektiv i den siste kulturmeldingen (Kulturdepartementet, 2018), og er også til stede i den foregående kulturmeldingen (Kultur- og kirkedepartementet, 2003).

Norsk akademia, og spesielt samfunnsvitenskapene, var raskt ute med å ta til seg Habermas' teorier; Den borgerlige offentlighet ble oversatt til norsk allerede i 1971, 18 år før den forelå på engelsk. Som 
nevnt $\mathrm{i}$ innledningen består norske offentlige utredningers utnevnte arbeidsgrupper ofte av en betydelig andel akademikere. Fordi mange norske samfunnsforskere er influert av Habermas' teorier, har teoriene også hatt sterk innflytelse på NOU'ene. Kalleberg (2015) har vist hvordan Habermas' teorier på flere måter hadde innflytelse på arbeidet til gruppen som leverte den offentlige utredningen om behovet for en revidering av Grunnlovens ytringsfrihetsparagraf (NOU 1999: 27), noe som ble vedtatt i Stortinget i 2004. Som vi skal se i neste del, har også den siste revideringen av den norske folkebibliotekloven fra 2014 et islett av habermasianske tanker om offentlighet. I loven spesifiseres det nå i et eget ledd i formålsparagrafen at "Folkebibliotekene skal være en uavhengig møteplass og arena for offentlig samtale og debatt" (Folkebibliotekloven, 2014, § 1).

I de kulturpolitiske dokumentene hevdes det at arkiver, biblioteker og museer i kraft av sin troverdighet og autoritet skal bidra som en positiv kraft og en motvekt til en fragmentert offentlighet. En annen løsning som gjentas i flere av dokumentene er et tettere samarbeid mellom kultursektoren og kunnskapssektoren. Dette skal hovedsakelig skje gjennom at kultur skal være en naturlig del av skole og utdanning. På den måten skal kulturen bidra til refleksjon, utvikling og dannelse, som ifølge argumentasjonen i kulturmeldingen indirekte fører til en styrket offentlighet.

Den siste bibliotekstrategien (Kulturdepartementet og Kunnskapsdepartementet, 2019) har flere beskrivelser av hvordan biblioteket skal være en sterk bidragsyter til opparbeidelse av digital medieog informasjonskompetanse for befolkningen, men i likhet med den forrige bibliotekstrategien (Kulturdepartementet, 2015) er det ingen konkrete eksempler på hvordan bibliotekene skal gjennomføre dette, utenom generelle målbeskrivelser.

\section{Bibliotekets rolle}

I det digitale informasjonssamfunnet ser man i kultur- og kunnskapspolitikken på bibliotekets rolle som en tilbyder av kvalitetssikret informasjon og kunnskap. Ved å heve bibliotekpersonalets digitale kompetanse skal bibliotekene være delaktige $\mathrm{i}$ å veilede og heve befolkningens kompetanse. Bibliotekene skal tilby veiledning i digitale tjenester, et mål som viser seg å være delvis oppfylt, da det i mange folkebiblioteker har blitt populært med arrangementer eller veiledning innen bruk av nettbrett eller grunnleggende internettjenester for eldre.

I lys av den reviderte folkebibliotekloven (Folkebibliotekloven, 2014), ser vi klare paralleller mellom bibliotekene som møteplass og konseptet den borgerlige offentlighet, ved at folkebibliotekene nå har fått lovfestet at de skal være et fysisk rom for samtale og debatt borgerne imellom. Men også før denne lovendringen hadde folkebibliotekene noen grunnfunksjoner som samsvarte med sentrale egenskaper ved en borgerlig offentlighet, spesielt den litterære borgerlige offentlighet.

I de dokumentene vi har studert blir bibliotekene beskrevet som sentrale for kunnskapservervelse, dannelse og myndiggjøring, og som en hjørnesten i den demokratiske infrastrukturen. Det er samtidig grunn til å ha et kritisk blikk på myndighetenes opphøyelse av bibliotekene som demokratiske kjerneinstitusjoner, da offentlige dokumenter av typen vi har analysert er normative i sin argumentasjon, og i liten grad viser til empiri som understøtter at bibliotekvesenet faktisk lever opp til de beskrivelsene som blir brukt om dets virke.

Over tid ser vi at bibliotekenes rolleforståelse har endret seg. Det er mye som taler for at nåtidens sterke fokus på digitale utfordringer ved informasjonssamfunnet også har innhentet biblioteksektoren. Tekster angående ekkokamre, informasjonskompetanse, offentlighet og demokrati fikk en langt tydeligere tilstedeværelse i bibliotekstrategien utgitt i 2019, enn i tidligere dokumenter. 


\section{Demokrati og offentlighet}

Flerfoldige utdrag fra Kulturens kraft (Kulturdepartementet, 2018) konsoliderer den habermasianske ideen om en rasjonell, åpen og kritisk offentlighet som et avgjørende bindeledd mellom en opplyst og kritisk tenkende befolkning og et levedyktig demokrati. I tillegg fremheves medie- og informasjonskompetanse som sentralt. Det settes et sterkt fokus på digitale ferdigheter og digital $\mathrm{d} \emptyset \mathrm{mmekraft}$ som nye fundamentale egenskaper for borgerne i dagens demokratier.

En rød tråd i alle de dokumentene vi har studert (Kultur- og kirkedepartementet, 2003; Kulturdepartementet, 2009, 2015, 2018; Kulturdepartementet og Kunnskapsdepartementet, 2019) er det sterke båndet mellom demokratiet og informerte og kritisk tenkende borgere, og viktigheten av en uavhengig offentlighet som et rom hvor borgerne kan møtes i samtale. Staten har i Norge lang tradisjon for å underst $\varnothing$ tte offentligheten på armlengdes avstand (Engelstad, Larsen \& Rogstad, 2017), og de dokumentene vi har studert kan sies å representere en kultur- og kunnskapspolitisk eksplisering av slike relasjoner.

\section{Konklusjon}

I Kulturens kraft (Kulturdepartementet, 2018) og Rom for demokrati og dannelse (Kulturdepartementet og Kunnskapsdepartementet, 2019) er det en tydelig erkjennelse av at digital informasjonsteknologi kan ha negative konsekvenser for demokratiet. Begge dokumentene har detaljerte beskrivelser av konkrete utfordringer for offentligheten og demokratiet. Ekkokammerdannelser, digitalt skapte filterbobler, falske nyheter og desinformasjon anses som problemer med potensiale til å skade det offentlige ordskiftet, befolkningens tillit til tradisjonelle medier og demokratiske prosesser. Det virker dermed åpenbart at norske myndigheter vier oppmerksomhet til disse emnene, og at de ser et behov for å agere tilstrekkelig på utfordringene.

Det er flere virkemidler Kulturdepartementet og Kunnskapsdepartementet anser som viktige for å løse de digitale utfordringene. På et teoretisk plan er løsningen at kultur (i den smale forstanden av begrepet [Larsen, 2019, s. 21-29]), skal virke forebyggende og forsterkende for befolkningens evne til medborgerskap. Den bakenforliggende ideen er at borgere som tilbys og benytter seg av kulturuttrykk av høy kvalitet vil utvikle evnen til å tenke kritisk. Kultur skal også virke stimulerende på leselyst og ferdigheter, kunnskapssøken og dannelse. I tillegg har kulturen en samlende funksjon ved at den muliggjør at mennesker med forskjellige bakgrunner og verdisyn kan møtes i en åpen og inkluderende offentlighet. Alle disse egenskapene skal motvirke en stadig mer fragmentert offentlighet. Denne forestillingen om kultur som et botemiddel er spesielt tydelig i den siste kulturmeldingen og den siste bibliotekstrategien. På et mer praktisk nivå nevnes arkiv, bibliotek og museum som institusjoner som skal formidle de kulturelle tilbudene. Begreper som folkeopplysning, dannelse, kunnskapstilegnelse og sosial utjevning er uttrykk som over lengre tid har vært tett forbundet med disse institusjonene. Beskrivelsene av institusjonenes virke og formål preges av tydelig normative idealer.

Bibliotekets rolle har endret seg markant i løpet av 2000-tallet. Mye av endringen har å gjøre med den reviderte folkebibliotekloven. Den gir folkebibliotekene en tydelig rolle som møteplass og arena for offentlig samtale og debatt, i tillegg til den tradisjonelle kulturformidlingsfunksjonen. I de analyserte dokumentene trer bildet av bibliotekene som kultur- og kunnskapstilbyder, og som demokratisk infrastruktur tydelig frem. I den siste bibliotekstrategien (Kulturdepartementet og Kunnskapsdepartementet, 2019) blir biblioteker beskrevet som "demokratihus" og som en "grunnstamme i demokratiet». Dette er uttrykk som godt representerer hvordan bibliotekene blir fremstilt også i de tidligere utgitte dokumentene. I en tid preget av ekkokamre, filterbobler og algoritmisk makt skal bibliotekene fungere som veiledere i digitale ferdigheter. 


\section{Referencer}

Bruns, A. (2019). Are Filter Bubbles Real? Cambridge: Polity Press.

Engelstad, F., Larsen, H. \& Rogstad, J. (2017). The public sphere in the Nordic Model. I F. Engelstad, H. Larsen, J. Rogstad \& K. Steen-Johnsen (Red.), Institutional Change in the Public Sphere. Views on the Nordic Model. Berlin: De Gruyter Open. https://doi.org/10.1515/9783110546330-004

Finlayson, J. G. (2005). Habermas: A Very Short Introduction: 125. United Kingdom: Oxford University Press.

Folkebibliotekloven. (2014). Lov om folkebibliotek. Oslo: Kulturdepartementet. https://lovdata.no/dokument/NL/lov/1985-12-20-108

Fredwall, I. E., Bergan, C., Bøyum, I., Holsve, M. N., Hultin, A. B., Olsen, H., K., Røgler, V. \& Tveit, Å. K. (2020). Nytt lovforslag svekker elevenes læringsmiljø. Aftenposten, 8. juni. https://www.aftenposten.no/meninger/debatt/i/lA6VbA/nytt-lovforslag-svekker-eleveneslaeringsmiljoe

Gentikow, B. (2009). Habermas, medienes rolle for den offentlige meningsdannelsen, og en fotnote om Internettet i fire versjoner. Norsk medietidsskrift, 16(1): 65-72.

https://www.idunn.no/nmt/2009/01/habermas_medienes_rolle_for_den_offentlige_meningsdannelsen og en fotnote $\mathrm{O}$

Grunnloven. (2004). Kongeriket Norges Grunnlov. Oslo. Justis- og beredskapsdepartementet. https://lovdata.no/dokument/NL/lov/1814-05-17-nn

Habermas, J. (1984). The Theory of Communicative Action. Reason and the Rationalization of Society. Boston: Beacon Press.

Habermas, J. (2005[1962]). Borgerlig offentlighet: dens fremvekst og forfall: en unders $\varnothing$ kelse omkring et av det borgerlige samfunns grunnbegreper. Oslo: De norske bokklubbenene.

Habermas, J. (1996). Between Facts and Norms: Contributions to a Discourse Theory of Law and Democracy. Cambridge, MA: MIT Press.

Habermas, J. (2006). Political communication in media society: Does democracy still enjoy an epistemic dimension? The impact of normative theory on empirical research. Communication Theory, 16(4): 411-426. https://doi.org/10.1111/j.1468-2885.2006.00280.x

Holst, C. (2019). Ekspertenes rolle i demokratiet. I Årbok 2018. Det Norske Videnskaps-Akademi. Oslo: Novus forlag.

https://www.duo.uio.no/bitstream/handle/10852/76796/Ekspertenes\%2brolle\%2bi\%2bdemokratie t.pdf?sequence $=2 \&$ isAllowed $=y$

Høibraaten, H. (2005). Innledende essay. I Borgerlig offentlighet: dens fremvekst og forfall (s. IXLVII). Oslo: De norske bokklubbenene.

Kalleberg, R. (2015). Ytringsfrihet, demokratiteori og demokratiet som uferdig prosjekt. Sosiologi $i$ dag, 45(4), 11-37. http://ojs.novus.no/index.php/SID/article/viewFile/1175/1166

Kalleberg, R. (2019). Offentlighet. I O. Korsnes (Red.), Sosiologisk leksikon (Revidert og utvidet utgave). Oslo: Universitetsforlaget. 
Kulturdepartementet. (2009). St.meld. nr. 23 (2008-2009) Bibliotek - Kunnskapsallmenning, møtestad og kulturarena i ei digital tid. Oslo: Kulturdepartementet.

https://www.regjeringen.no/contentassets/6a7ad6f5ba584c8aafdc8bfa5cba86b1/nnno/pdfs/stm200820090023000dddpdfs.pdf

Kulturdepartementet. (2015). Nasjonal bibliotekstrategi 2015-2018. Oslo: Kulturdepartementet. https://www.regjeringen.no/contentassets/e1dd0466444d4d5d9d02e8d6897d38fb/nasjonal_biblioteks trategi_2015-2018.pdf

Kulturdepartementet. (2018). Meld. St. 8 (2018-2019) Kulturens kraft. Oslo: Kulturdepartementet. https://www.regjeringen.no/contentassets/9778c28ab1014b789bbb3de0e25e0d85/nnno/pdfs/stm201820190008000dddpdfs.pdf

Kultur- og kirkedepartementet. (2003). St.meld. nr. 48 (2002-2003) Kulturpolitikk fram mot 2014. Oslo: Kultur- og kirkedepartementet.

https://www.regjeringen.no/contentassets/382efb47f7474108b2e8172009885cd9/no/pdfs/stm200220 030048000dddpdfs.pdf

Kulturdepartementet og Kunnskapsdepartementet. (2019). Nasjonal bibliotekstrategi 2020-2023 Rom for demokrati og dannelse. Oslo: Kulturdepartementet og Kunnskapsdepartementet. https://www.regjeringen.no/contentassets/18da5840678046c1ba74fe565f72be3d/nasjonalbiblioteksstrategi-endelig-uu.pdf

Larsen, H. (2019). Den nye kultursosiologien: kultur som perspektiv og forskningsobjekt (2. utgave. utg.). Oslo: Universitetsforlaget.

Moe, H., Hovden, J. F., Ytre-Arne, B., Figenschou, T. U., Nærland, T. U., Sakariassen, H. \& Thorbjørnsrud, K. (2019). Informerte borgere? Offentlig tilknytning, mediebruk og demokrati. Oslo: Universitetsforlaget.

Morozov, E. (2012). The Net Delusion: The Dark Side of Internet Freedom. USA: PublicAffairs.

NOU 1999: 27. (1999). "Ytringsfrihed bør finde Sted» - Forslag til ny Grunnlov § 100. Oslo: Justis- og beredskapsdepartementet.

https://www.regjeringen.no/contentassets/026a9879891a4972b019ce10f20561fe/no/pdfa/nou199919 990027000dddpdfa.pdf

NOU 2013: 4. (2013). Kulturutredningen 2014. Oslo: Kulturdepartementet. https://www.regjeringen.no/contentassets/1e88e03c840742329b9c46e18159b49c/no/pdfs/nou201320 130004000dddpdfs.pdf

NOU 2019: 23. (2019). Ny opplæringslov. Oslo: Kunnskapsdepartementet. https://www.regjeringen.no/contentassets/3a08b44df1e347619e32db47d13ac0cd/no/pdfs/nou201920 190023000dddpdfs.pdf

Pariser, E. (2011). The Filter Bubble. London: Penguin Random House.

Solheim, P. A. (2020). Det digitale informasjonssamfunnet, demokratiet og offentligheten. Kultur-og bibliotekpolitikk i en digital tid (Masteroppgave). OsloMet - storbyuniversitetet. https://odahioa.archive.knowledgearc.net/bitstream/handle/10642/9176/Solheim_mbib2020.pdf?sequence=2

Sunstein, C. R. (2001). Republic.com. Princeton, NJ: Princeton University Press. 
Sunstein, C. R. (2009). Republic.com 2.0. Princeton, NJ: Princeton University Press.

Sunstein, C. R. (2018). \#Republic: Divided Democracy in the Age of Social Media. Princeton, NJ: Princeton University Press.

Valtysson, B. (2020). Digital Cultural Politics. From Policy to Practice. Cham: Palgrave Macmillan.

Zuboff, S. (2019). The Age of Surveillance Capitalism: The Fight for a Human Future at the New Frontier of Power. New York: PublicAffairs.

\footnotetext{
' Den siste bibliotekstrategien er samforfattet av Kulturdepartementet og Kunnskapsdepartementet, siden den omfatter både folke- og fylkesbiblioteker, som ligger under Kulturdepartementet, og skole-, universitets- og høyskolebiblioteker, som ligger under Kunnskapsdepartementet.

ii Habermas' teorier om demokrati og offentlighet er ikke de eneste perspektivene på dette temaet som har influert kultur- og bibliotekpolitikken. Vi velger likevel å begrense vår diskusjon til Habermas' perspektiver, siden disse har hatt spesielt stor innflytelse, og vi i tillegg ser at de demokratiske utfordringer forbundet med den digitale teknologien og de sosiale mediene i stor grad settes i sammenheng med et Habermas-inspirert perspektiv på demokrati og offentlighet.

iii De andre dokumentene er grundigere analysert i Solheim (2020).

iv Etter oppløsningen av det statlige forvaltningsorganet ABM-utvikling i 2010, ble statlige oppgaver knyttet til folke- og fylkesbibliotekene flyttet til Nasjonalbiblioteket, mens oppgaver knyttet til museum og arkiv ble flyttet til Norsk kulturråd.

v Denne stortingsmeldingen er skrevet på nynorsk. Vi har valgt å gjengi sitatene i sitt originale språk.

vi Grunnlovens paragraf 100 ble revidert av Stortinget i 2004, etter forslag fra et offentlig utvalg (NOU 1999: 27).

vii Den reviderte paragrafen inneholder et ledd hvor det spesifiseres at «[D]et påligger statens myndigheter å legge forholdene til rette for en åpen og opplyst offentlig samtale» (Grunnloven, 2004). Dette leddet omtales gjerne som infrastrukturkravet i Grunnlovens ytringsfrihetsparagraf, siden den viser til statens ansvar for å sikre ytringsfrihetens infrastruktur, gjennom en aktiv kultur-, medie-, utdannings- og forskningspolitikk.

viii Flere har imidlertid i det siste ytret bekymring for skolebibliotekenes fremtidige rolle (Fredwall et al., 2020), siden den norske opplæringsloven er foreslått endret slik at det ikke lenger er spesifisert at alle elever skal ha tilgang til et skolebibliotek, men kun tilgang til et bibliotek (NOU 2019: 23). Ifølge kritikerne kan dette lede til at de allerede eksisterende folkebibliotekene også skal fungere som skolebibliotek uten nærmere tilrettelegging for elevene.
} 